\title{
A classificação e a avaliação de documentos: análise de sua aplicação em um sistema de gestão de documentos arquivísticos digitais
}

Murilo Billig Schäfer

Mestrando do Programa de Pós-Graduação em Patrimônio Cultural da Universidade Federal de Santa Maria (UFSM).Arquivista da Universidade Federal da Fronteira Sul (UFFS).

Eliseu dos Santos Lima

Acadêmico da Pós-Graduação Lato Sensu Gestão em Arquivos da Universidade Federal de Santa Maria (UFSM).Arquivista da Universidade Federal da Fronteira Sul (UFFS).

Na busca por maior agilidade e eficácia na realização de suas atividades, as organizações utilizam, cada vez mais, os documentos arquivísticos digitais. As características desses documentos - detentores de informações indispensáveis para a consecução dos objetivos organizacionais - permitem o acesso facilitado às informações, agilidade no desenvolvimento de projetos, compartilhamento simultâneo da informação entre indivíduos e organizações, além de promover a difusão de acervos culturalmente relevantes. Entretanto, para que tais características possam ser usufruídas, é imprescindível a adoção da gestão de documentos e informações nos ambientes digitais, apresentando-se como um desafio ao atual contexto tecnológico informacional. Neste sentido, este estudo apresenta os principais elementos identificados quando da aplicação da classificação e avaliação de documentos arquivísticos, em um Sistema de Gestão de Documentos Digitais (SGDD), de acordo com as orientações do Modelo de Requisitos para Sistemas Informatizados de Gestão Arquivística de Documentos - e-ARQ Brasil, analisando suas implicações. Tal iniciativa serve de auxilio no estabelecimento de projetos que visem à gestão documental em meio digital, ao mesmo tempo em que compartilha experiências e conhecimentos para o desenvolvimento da tecnologia aplicada à informação. 
Palavras-chave: Classificação de documentos; Avaliação de documentos; Sistemas informatizados.

\section{Evaluation and classification of documents: an analysis of its aplication in a digital archival document management system}

Organizations, in an attempt to increase speed and efficiency for carrying out their activities, have been increasing the use of digital records. These documents carry essential information for obtaining organizational objectives and their characteristics allow easier access to information, flexibility in project development, simultaneous sharing of information between individuals and organizations, and promote the dissemination of culturally relevant collections. However, for benefiting of such features it is necessary to adopt the management of documents and information in digital environments, which can be a challenge to the current technological context of information. Thus, this study presents the main elements identified in the application of classification and evaluation of records in a System of Digital Document Management DRMS - in accordance with the guidelines of the Model Requirements for Information Systems Management of Archival documents - and ARQ-Brasil, and its implications were analyzed. This initiative serves as an aid for establishing projects that aim to manage documents in digital media, while sharing experiences and knowledge for the development of technology applied to information.

Keywords: Classification of documents; Assessment documents; Computerized systems.

Recebido em 02.04.2012 Aceito em 08.05.2012

\section{Introdução}

O avanço tecnológico atinge a sociedade atual de maneira irreversível. Os modos de comunicação, as relações sociais, as formas de aprendizado, a realização de atividades administrativas, entre tantas outras tarefas, modificam-se e evoluem em velocidade surpreendente, graças à tecnologia. Inevitavelmente, o mesmo acontece no contexto da 
produção de informações, especialmente as de caráter arquivístico, que transcendem do clássico suporte papel para o meio digital.

Frente a isso, as organizações, tanto públicas quanto privadas, buscam meios de gerenciar seus ativos informacionais, que fogem do simples arquivo em papel e transformam-se em centros de informações e conhecimento compostos por cadeias de bits. Os arquivistas, até então voltados predominantemente para os meios de gerenciamento de documentos físicos, deparam-se com um dilema que vem confrontando sua atuação profissional: como gerenciar as informações em meio digital de forma que estejam disponíveis aos seus usuários, mantendo a integridade e autenticidade? A complexidade da questão avança para a necessidade de acessibilidade e preservação de longo prazo dessas informações.

Neste contexto, expõe-se, no presente estudo, uma reflexão sobre a experiência da implantação de um $\operatorname{SGDD}^{1}$ na Universidade Federal da Fronteira Sul (UFFS), com ênfase nas atividades de classificação e avaliação dos documentos arquivísticos. Tal sistema destaca-se por adotar o Modelo de Requisitos para Sistemas Informatizados de Gestão Arquivística de Documentos - e-ARQ Brasil, em suas funcionalidades, gerenciando parte dos documentos arquivísticos da Instituição.

São apresentadas as características mais relevantes na tarefa de classificar e avaliar os documentos em um ambiente eletrônico, considerados sob a perspectiva arquivística. As repercussões desta análise servem como contribuição para demais organizações que custodiam documentos em meio digital, agregando as tarefas da gestão de documentos nos ambientes eletrônicos. No contexto brasileiro, são raras as iniciativas voltadas à gestão de informações arquivísticas digitais. Este relato e seus desdobramentos, constituem-se em um compromisso com a profissão e sociedade, analisando se as instituições estão preparadas para a gestão da informação arquivística digital.

\section{Referencial teórico}

\subsection{Gestão de documentos e informações: perspectivas}

Independente de sua estrutura, finalidade, área de atuação ou mesmo personalidade (pública ou privada), todas as organizações produzem documentos arquivísticos para executar suas atividades e atingir seus objetivos. Ou seja, é consenso que toda organização depende determinantemente dos ativos informacionais para se manter estruturada e atuante. Entretanto, isso não representa a garantia de que as informações serão adequadamente gerenciadas.

Neste sentido, os profissionais da informação, dando destaque ao arquivista, tem como ação do seu trabalho a gestão de documentos e informações, que, segundo Ribeiro (2010), estrutura-se, como:

\footnotetext{
${ }^{1}$ Sistema de Gestão de Documentos Digitais.
} 
A gestão documental significa a sobrevivência, competitividade de uma instituição. Conduz à transparência das atividades, possibilitando a governança e o controle das informações; documenta as atividades de pesquisa, desenvolvimento, assegura, de forma eficiente, a produção, administração, manutenção e destinação; eliminação dos documentos que não tenham valor administrativo fiscal, legal ou para pesquisa científica e histórica; assegura o uso adequado de processamento automatizado de dados; contribui para o acesso e preservação dos documentos que fazem jus à guarda permanente; faz com que a instituição reformule o seu fazer arquivístico (RIBEIRO, 2010, p. 4).

Pela perspectiva apresentada acima, a existência, funcionamento e desenvolvimento de toda organização baseia-se na informação orgânica, registrada nos documentos arquivísticos. Significa afirmar que a sobrevivência de uma organização depende da informação arquivística. Carvalho e Longo (2002) complementam que os arquivos constituem-se em centros ativos de informação e precisam estar devidamente organizados e estruturados para atingirem seus objetivos, que são atender à administração, evitar erros e repetições desnecessárias, produzir conhecimento para assessorar as tomadas de decisão e dar continuidade aos trabalho das instituições.

A necessidade da gestão documental assume maior importância quando se tratam das organizações públicas, pois a informação produzida e a informação custodiada, nestas unidades, são reflexo do caráter público e social, que devem servir ao coletivo, ou seja, ao bem comum. Consequentemente, tais informações são de acesso garantido - inclusive com previsão constitucional -, ao público que delas se relacionam.

Os desafios para a efetivação da gestão de documentos e informações aumentam pela falta de consciência dos gestores frente ao tema, inexistência ou escassez de recursos financeiros, humanos e tecnológicos e, principalmente, pela cultura organizacional arraigada e inflexível, que não incentiva as mudanças necessárias, para se efetivar um contexto organizacional pautado no uso racional da informação.

Embora os desafios se apresentem - com maior ou menor intensidade - em todas as organizações, as iniciativas de órgãos responsáveis pela definição de políticas de gestão documental (citando-se, como exemplos, o Arquivo Nacional e o $\mathrm{CONARQ}^{2}$ ), aliadas à atuação dos arquivistas, promovem perceptíveis mudanças no cenário da gestão de documentos e informações. Segundo Carvalho e Longo (2002), infere-se que:

Nesse novo cenário, as organizações encontrarão na informação, no conhecimento e no planejamento, os elementos que irão direcionar suas tomadas de decisão, uma

\footnotetext{
${ }^{2}$ Conselho Nacional de Arquivos.
} 
vez que, quanto mais incertezas surgirem no ambiente organizacional, maiores serão as dificuldades encontradas pelos dirigentes para programar e rotinizar suas atividades, necessitando, assim, que um maior número de informações sejam processadas em apoio de suas tarefas. (CARVALHO e LONGO, 2002, p. 114).

Nas organizações públicas, as mudanças ocorrem em um ritmo lento, demandando ações e projetos adequadamente planejados, que tenham por finalidade o acesso, promoção e uso racional das informações. Com a crescente quantidade de iniciativas, visando ao reconhecimento do valor da informação arquivística, inicia-se um despertar na consciência dos gestores públicos frente ao tema, criando perspectivas propicias à atuação dos arquivistas.

A gestão de documentos arquivísticos (atividade primordial do arquivista), pauta-se na aplicação de funções que promovem o controle das informações, desde sua criação, até a destinação final. Segundo Rousseau e Couture (1998), são sete as funções arquivísticas: a criação, a avaliação, a aquisição, a conservação, a classificação, a descrição e a comunicação. Neste trabalho, são destacadas duas delas: a classificação e a avaliação.

\subsection{Funções arquivísticas: a classificação e a avaliação em foco}

As funções de classificação e avaliação são essenciais para a gestão dos documentos, pois permitem que as informações sejam organizadas racionalmente - facilitando a sua recuperação - e, quando não investidas de valor administrativo, histórico ou cultural, sejam adequadamente eliminadas.

De acordo com Lopes (1997), a classificação pode ser descrita como a sequência de operações que, de acordo com as estruturas organizacionais, funções e atividades de uma organização, visam a distribuir os documentos em classes e subclasses. Bernandes e Delatorre (2008) descreve que entre os objetivos e benefícios da classificação, destacam-se: a recuperação do contexto original de produção de documentos, visibilidade às funções, subfunções e atividades do organismo produtor, controle de trâmites, atribuição de códigos numéricos, além de fornecer subsídios para a avaliação dos documentos.

A avaliação de documentos, fase posterior à classificação, cumpre a função de descartar o que não seja de interesse para as atividades das organizações, como, também, para a sociedade em geral, que busca informações para conhecer seu meio, seu passado e constituir uma identidade. Frente a isso, os critérios de avaliação devem ser pautados na visão crítica dos possíveis usos da informação arquivística. Bernardes e Delatorre (2008) explicam que existem documentos que jamais podem ser eliminados, pois comprovam fatos e atos fundamentais para nossa 
existência civil e para nossa vida pessoal. Ao mesmo tempo, não é possível e nem desejável que todos os documentos sejam preservados, afinal, documentos que cumprem uma função importante durante determinado tempo, posteriormente, perdem o seu valor original, devendo ser eliminados, para que não dificultem o acesso a outros documentos com valor informativo e probatório relevantes.

Os principais instrumentos que possibilitam a classificação e avaliação de documentos são, respectivamente, o plano de classificação e a tabela de temporalidade. Ambos devem ser constituídos com referência aos preceitos arquivísticos (de organicidade, coerência, adaptabilidade, etc.), adequando-se ao contexto de produção informacional. A construção de um plano de classificação é observada por Gonçalves (1998), na qual:

Definir atividades-fim e atividades-meio e relacioná-las a funções mais abrangentes já significa reunir elementos para a classificação dos documentos. A reunião lógica de funções e atividades, com a percepção de sua maior ou menor autonomia ou subordinação interna, permitirá a elaboração do plano de classificação(GONÇALVES, 1998, p. 22).

O estabelecimento das classes e subclasses de um plano de classificação pode ser por três critérios: funcional, no qual as classes correspondem à função dos documentos; estrutural, de acordo com a estrutura organizacional de determinada instituição; e, por assunto, referente aos conteúdos registrados nos documentos. A definição de qual método é o mais adequado, por consenso, torna-se uma definição do arquivista, que deve analisar o contexto de produção documental em que atua, partindo da premissa de conseguir adequar o instrumento no ambiente organizacional, como elemento associado às atividades administrativas, como acrescenta Gonçalves (1998, p. 23), "a elaboração do plano não pode estar desconectada da preocupação com sua aplicação".

Enquanto isso, a tabela de temporalidade de documentos é definida por Bernardes e Delatorre (1998) como um instrumento aprovado por autoridade competente, que regula a destinação final dos documentos, definindo prazos para a guarda dos documentos em função de seus valores administrativos, legais e fiscais, determinando os prazos para sua transferência, recolhimento ou eliminação. A tabela de temporalidade pode ser considerada o principal instrumento do processo de avaliação de documentos, proporcionando, como resultados práticos, a inexistência de massas documentais acumuladas e o descarte de informações supérfluas. Por ser um processo que requer procedimentos legais (inclusive atendendo prazos definidos em lei para execução de determinadas tarefas do processo), a avaliação de documentos requer atenção redobrada pelos arquivistas, para que sua efetivação não seja comprometida.

Considerando o contexto do Poder Executivo Federal brasileiro, e, mais especificamente, as Instituições Federais de Ensino Superior (IFES), 
o Arquivo Nacional, através do $\mathrm{SIGA}^{3}$, desenvolvem-se ações que visam a padronizar as ações de gestão documental nos órgãos integrantes do sistema. Os instrumentos que servem de referência são o Código de Classificação, Temporalidade e Destinação de Documentos de Arquivo Relativos às Atividades-Meio da Administração Pública e a Tabela de Temporalidade e Destinação de Documentos de Arquivo Relativos às Atividades-Fim das Instituições Federais de Ensino Superior (IFES).

Segundo o Arquivo Nacional (2001), a adoção desses instrumentos, além de possibilitar o controle e a rápida recuperação de informações, orienta as atividades de racionalização da produção e fluxo documentais, avaliação e destinação dos documentos, aumentando a eficácia dos serviços arquivísticos da administração pública em todas as esferas.

Portanto, o desenvolvimento da gestão de documentos e informações interfere na qualidade das informações utilizadas pelas organizações e, para atingir esse objetivo, as adoções de instrumentos voltados à classificação e avaliação tornam-se indispensáveis.

\subsection{Tecnologia da Informação (TI) e Gestão Eletrônica de Documentos (GED)}

A informação utilizada na sociedade atual não remete, como outrora, à exclusividade ao suporte físico. As informações produzidas e utilizadas unicamente pelo mundo dos bits aumentam em escala vertiginosa, apresentando-se como um paradigma aos cientistas da informação. Muito embora, a informação necessita estar gravada ou mantida em determinada mídia ou repositório, o que se salienta é a mudança de escopo do trabalho dos profissionais da informação, que passam a gerenciar não unicamente os suportes, mas, também, a estruturação lógica e conceitual da informação.

Considerando essa mudança, é necessário compreender o conceito da tecnologia da informação, que, segundo Balloni (2003), configura-se, como,

O recurso tecnológico e computacional para geração e uso da informação utilizada para criar, armazenar, difundir dados e informação na criação do conhecimento [...] pode ser todo e qualquer dispositivo que tenha capacidade para tratar dados ou informações (BALLONI, 2003, p. 10).

A interferência da tecnologia da informação no trabalho do arquivista é perceptível, quando observa-se a necessidade da gestão arquivística de documentos e informações no meio digital. Negreiros (2007) esclarece que as tecnologias da informação estão influenciando os sistemas de gestão de arquivos em todos os âmbitos. Como a tecnologia é responsável por diversas transformações sociais, também o é no contexto intelectual, profissional e funcional. O autor destaca que, frente ao documento tradicional, surge o documento eletrônico, que promete ser

\footnotetext{
${ }^{3}$ Sistema de Gestão de Documentos de Arquivo da Administração Pública Federal.
} 
manipulável, rapidamente transformável e localizável, instantaneamente transportável e copiado infinitamente.

Frente à necessidade de gerenciar os documentos eletrônicos ${ }^{4}$, surgiu a tecnologia de Gerenciamento Eletrônico de Documentos (GED), que constitui-se em uma ou mais tecnologias aplicadas à gestão documental, abrangendo a classificação, avaliação, captura, e/ou demais procedimentos. O Conarq (2011, p. 10) define GED como "conjunto de tecnologias utilizadas para organização da informação não-estruturada de um órgão ou entidade, que pode ser dividido nas seguintes funcionalidades: captura, gerenciamento, armazenamento e distribuição".

O grande desafio do GED é potencializar suas funcionalidades integradas à gestão arquivística de documentos, o que, na maioria das vezes, não ocorre. Os procedimentos efetivam-se de forma "compartimentada", não constituindo uma gestão sistêmica da informação. Flores (2000) destaca essa questão:

O sistema de GED deveria possibilitar que o profissional da informação interagisse com este, pois seria possível desenvolver todo um trabalho arquivístico assistido pelo computador, constituindo-se efetivamente em gerenciamento eletrônico de documentos e desempenhando todas as funções arquivísticas, e não servindo somente para hospedar informações que já foram tratadas arquivisticamente de uma forma tradicional (FLORES, 2000, p. 76).

Outro fator que se soma às limitações do GED, é a necessidade das organizações em promoverem a gestão dos documentos nato-digitais, ou seja, que são criados, tramitados, eliminados e/ou arquivados exclusivamente em meio digital. O GED atende, e muito, a documentos em meio físico que, por determinadas razões, necessitaram ser transpostos para ambientes digitais. Entretanto, essa transposição não garante a validade legal para o "novo" documento digital, repercutindo em limitações ao uso dessas informações, principalmente em ambientes em que a qualidade probatória e de autenticidade são preponderantes.

A solução encontrada para a gestão dos documentos nato-digitais foi o desenvolvimento de sistemas informatizados de gestão arquivística de documentos (SIGAD). O Conarq (2011) apresenta a diferenciação entre GED e SIGAD, de forma objetiva.

Um GED trata os documentos de maneira compartimentada, enquanto o SIGAD parte de uma concepção orgânica, qual seja, a de que os documentos possuem uma inter-relação que reflete as atividades da instituição que os criou. Além disso, diferentemente do SIGAD, o GED nem sempre incorpora o conceito arquivístico de ciclo de vida dos documentos. (CONARQ, 2011, p. 11).

\footnotetext{
${ }^{4}$ Embora, neste artigo, seja empregada a nomenclatura "documento eletrônico", o foco principal do relato detém-se nos documentos digitais (constituídos por bits).
} 
De acordo com a citação, um SIGAD pressupõe todas as tarefas da gestão documental e, por conseguinte, gerencia o documento arquivístico em todas as fases, do arquivo corrente, passando ao intermediário, até ser eliminado ou armazenado permanentemente.

Como subsídio para as organizações frente à implantação de SIGAD's, cita-se o Modelo de Requisitos para Sistemas Informatizados de Gestão Arquivística de Documentos (e-ARQ Brasil), documento produzido pelo CONARQ - através da Câmara Técnica de Documentos Eletrônicos (CTDE), que como consta no próprio e-ARQ (2011), apresenta como objetivos, orientar a implantação da gestão arquivística de documentos digitais e não digitais, fornecendo especificações técnicas e funcionais, além de metadados, visando a orientar a aquisição e/ou especificação e desenvolvimento de sistemas informatizados de gestão arquivística de documentos.

Embora o e-ARQ e demais publicações de caráter normativo e orientador, sirvam como subsídios para a efetiva gestão documental em meio digital, as iniciativas frente a esse tema são tímidas, se considerarmos o âmbito público. Rondinelli (2004) apresenta a perspectiva de que, no contexto brasileiro, a parceria entre o Conarq a comunidade acadêmica e as iniciativas governamentais, possibilita condições para o estabelecimento de uma política de implementação de sistemas eletrônicos para gerenciamento arquivístico de documentos.

Considerar a gestão e, também, a preservação dos documentos e informações arquivísticas digitais, deve ser "compreendido" como uma necessidade pelas organizações. Suas atividades dependem, cada vez mais, desses elementos constituídos de bits e sua gestão é elemento primordial em um contexto tão dependente da evolução tecnológica.

\subsection{A informação digital: o novo cenário arquivístico}

Com a concepção dos documentos e informações arquivísticas digitais nas mais diversas áreas e atividades das organizações, apresentase um novo cenário para a gestão documental. O "clássico" arquivista, responsável por acervos exclusivamente em suporte físico, preocupado com a durabilidade do papel, é desafiado a gerenciar informações em ambientes virtuais, dando um sentido inovador e necessário para a evolução de sua profissão.

O Conselho Internacional de Arquivos (CIA), através do documento Estudo N. ${ }^{\circ}$ 16, argumenta sobre a mudança do perfil deste profissional.

Este desafio não é opcional: perderão influência e relevância a menos que desenvolvam soluções para responder às necessidades dos seus clientes em matéria de arquivos electrônicos. Mas se responderem estrategicamente, reposicionando-se institucional e profissionalmente, as perspectivas são optimistas. Para isso têm de adquirir novas competências e aprender a trabalhar com terceiros que detêm as competências necessárias à gestão dos documentos de 
arquivo electrónicos [...] uma gestão de documentos passiva e defasada no tempo acaba por se tornar irrelevante (CIA, 2005, p. 27).

O novo perfil do arquivista não visa a modificar sua responsabilidade de desenvolver práticas arquivísticas consagradas (como a classificação, a avaliação, a difusão, entre outras, fundamentais para a gestão de documentos arquivísticos), mas é necessário encontrar soluções para a aplicação de tais atividades nos ambientes eletrônicos, para que as informações digitais mantenham o caráter arquivístico e cumpram as funções para as quais foram criadas.

A transição do contexto informacional para o meio digital dependerá dos diversos profissionais que atuam na gestão da informação e não unicamente do arquivista. Brito (2005, p. 47) expõe que "os novos desafios que surgem para o profissional da Arquivística o convidam a desenvolver conhecimentos comuns com profissionais de outras áreas, em especial com os cientistas da informação e com os tecnólogos da informática". Corroborando com a ideia, o CIA (2005) acrescenta que as organizações que já estão envolvidas com a gestão e preservação de documentos de arquivo eletrônicos, concluíram que as competências de tecnologias da informação (gestão de sistemas e/ou desenvolvimento de software) e as competências arquivísticas são igualmente necessárias e, ainda, que cada especialista deve possuir conhecimentos básicos sobre o papel do outro.

Tomando-se como cenário as organizações públicas brasileiras (e considerando o contexto deste estudo), a implantação de sistemas de gestão de informações digitais constituem-se em exemplos de integração entre diferentes profissionais - com destaque para o arquivista e os profissionais da TI -, visando a efetiva gestão documental e informacional.

Frente a isso, o CIA (2005) afirma que:

Os arquivistas devem concentrar-se particularmente nos sistemas de arquivo onde sejam produzidos documentos com valor secundário. Devem monitorizar estes sistemas durante todo o seu ciclo de vida e participar de todas as grandes decisões que lhes respeitam de forma a assegurar que os documentos destinados à preservação a longo prazo mantêm as suas características essenciais até que sejam transferidos para o controle de uma instituição de arquivo. (CIA, 2005, p. 29).

Entretanto, a atuação conjunta dos profissionais não se constitui em uma tarefa simples. Além da necessidade de direcionar as distintas visões profissionais para objetivos comuns, torna-se necessário a conscientização dos gestores da instituição, como, também, dos envolvidos com a produção e uso da informação para a importância desse processo.

Novamente considerando o CIA (2005), acrescenta-se que este defende que a gestão de documentos é essencial para todas as atividades 
do governo e da administração pública. Contudo, muitos dirigentes não percebem os documentos que produzem como parte da gestão de documentos e arquivos. É necessário que os arquivistas se conscientizem sobre as atividades que desenvolvem, como, também, para as competências e possibilidades de apoio que a profissão tem a oferecer. Acrescenta-se, ainda, a incorporação da gestão de documentos de arquivo (considerando todo o seu ciclo de vida) no trabalho das organizações.

A conscientização para o enfrentamento do novo cenário informacional não recai como responsabilidade unicamente dos arquivistas, cientistas da informação ou dos profissionais da TI. As próprias organizações demonstram não estar preparadas para lidar com sua desenfreada produção informacional em meio digital. Carvalho e Longo (2002) expõem que, muitas vezes, adotam-se medidas paliativas, incorporando novas tecnologias que são encaradas como solução para o problema da existência desses arquivos. Enquanto não tiverem seu principal produto contextualizado e organizado para facilitar sua recuperação e sua transmissão, eles não produzirão conhecimento.

O descaso e a inexperiência na gestão de documentos e informações digitais representam lacunas e perdas de informações sob custódia das organizações. É um cenário associado à evolução tecnológica, que, ao mesmo tempo em que proporciona desenvolvimento, se contrapõe, ao não apresentar soluções consistentes para as mudanças que desencadeia.

Portanto, as iniciativas de gestão e preservação devem ser estimuladas e compartilhadas, de modo a relacionar o novo cenário informacional, não como um período de perda de informações cruciais para o desenvolvimento da sociedade, mas como o desenvolvimento e aperfeiçoamento de ferramentas tecnológicas que auxiliam na construção social, produção de conhecimento e valorização das fontes documentais.

\section{Metodologia}

Como este estudo constitui-se na análise e reflexão sobre a aplicação da tecnologia voltada à gestão da informação arquivística, a metodologia utilizada baseou-se em dois aspectos: levantamento de referencial teórico e análise da classificação e avaliação dos documentos em um SGDD, neste caso, considerando o contexto documental da UFFS.

A revisão dos principais conceitos da teoria arquivística frente ao tema gestão de documentos e informações possibilitou uma compreensão das implicações que este processo proporciona em uma organização. Dessa forma, adquire-se conhecimento teórico para direcionar os esforços na aplicação prática da gestão documental.

Quanto à análise da classificação e avaliação de documentos arquivísticos no SGDD, elencou-se as principais características da aplicação dessas atividades arquivísticas, no tópico $A$ classificação $e$ avaliação de documentos arquivísticos aplicadas em um SGDD. 
Portanto, o conhecimento teórico, conjuntamente à análise prática, constituiu-se como fundamentos para o desenvolvimento do estudo

\section{A classificação e a avaliação de documentos arquivísticos aplicadas em um SGDD}

As características relatadas, neste tópico, referem-se à classificação e à avaliação dos documentos arquivísticos gerenciados através de um SGDD que atende aos requisitos do e-ARQ Brasil. Considerando que os ambientes tecnológicos mantêm-se em constante aperfeiçoamento, modificações realizadas ao longo do tempo, podem descaracterizar determinados elementos descritos neste estudo.

Por questões de delimitação do escopo do trabalho, são citados apenas os elementos considerados mais relevantes para a classificação e a avaliação dos documentos arquivísticos em um SGDD, não sendo possível transcorrer sobre todos os requisitos que o e-ARQ pressupõe para estas duas funções arquivísticas. Acrescenta-se que a abordagem sobre o SGDD, refere-se tanto para os documentos nato-digitais (criados e utilizados em meio digital), quanto aos convencionais (criados em meio físico e apenas referenciados no sistema).

\subsection{Classificação dos documentos em um SGDD}

\subsubsection{Desenvolvimento da classificação de documentos}

Um dos principais desafios da classificação de documentos é a conscientização dos setores que utilizam a informação arquivística, sobre os benefícios proporcionados, quando da aplicação de um código ou plano de classificação para a recuperação da informação. Frente a isso, torna-se comum que organizações apresentem instrumentos de classificação de caráter oficial, mas que não são efetivamente aplicados nas unidades produtoras de documentos.

Com o uso de um SGDD, o "descaso" com a efetivação da classificação dos documentos pode ser minimizado, pois, no momento de inserção de um objeto digital para tramitação (nato-digital ou convencional), apresenta-se, como requisito "obrigatório", a definição de classes e subclasses a que se refere o documento. Isso impossibilita que os objetos digitais sejam inseridos em um sistema, sem a definição do nível a qual pertencem, referente ao instrumento de classificação de documentos da instituição ${ }^{5}$, evitando o que ocorre, ocasionalmente, no meio físico, no qual a classificação acaba por se tornar uma prática "opcional".

\footnotetext{
5 No caso da UFFS, a classificação dos documentos arquivísticos é realizada de acordo com o Código de Classificação de documentos de arquivo para a Administração Pública: Atividades-Meio e Código de Classificação de Documentos de Arquivo relativos às atividades-fim das IFES.
} 
O sucesso na tarefa de classificação dos documentos arquivísticos (digitais ou físicos) depende fundamentalmente da orientação dada aos responsáveis pela produção e/ou organização dos documentos nas unidades administrativas de uma instituição. Além de uma orientação inicial, é necessário que os arquivistas assessorem continuamente as unidades detentoras de documentos, pois equívocos na classificação representam alterações no ciclo de vida determinado pela temporalidade do documento. Neste sentido, podemos tomar como exemplo um documento que de acordo com as funções e/ou assunto, apresenta uma temporalidade de 5 anos na fase corrente (atendendo à atividades administrativas) e, posteriormente, destina-se à eliminação. Caso seja classificado equivocadamente em outra classe ou subdivisão que não reflete suas funções e/ou conteúdo, seu ciclo de vida apresentará distintas definições de prazos e guarda (e, por vezes, indevidas). Isso representa sérias implicações no momento da avaliação, pois documentos vigentes ou que não cumpriram seus prazos precaucionais, em hipótese alguma podem ser eliminados, pois além de apresentarem informações que ainda podem atender atividades administrativas, vão de encontro aos preceitos legais quanto à eliminação de documentos de caráter público.

No caso de um SGDD, as implicações da classificação equivocada são as mesmas que as no meio físico. Por mais que o sistema seja evoluído tecnologicamente, a tarefa de classificar os documentos permanece como atividade inerente ao indivíduo. Reitera-se, portanto, que a tecnologia não é capaz de dirimir a importância da compreensão por parte dos envolvidos, não só para a classificação, mas para toda a gestão documental de uma Instituição.

Desse modo, a tarefa de orientar as unidades custodiadoras de documentos arquivísticos para a classificação, por mais que demande tempo e comprometimento, representa a consecução do ciclo de vida dos documentos, primordial para a efetividade da gestão documental

\subsubsection{Gerenciamento da classificação de documento}

Os sistemas eletrônicos adotam diversas funcionalidades para delimitar ações ou atribuir responsabilidades a cada indivíduo que interage com sua interface. Para o SGDD da UFFS, utiliza-se a definição de perfis de usuários, que delimitam determinadas ações para cada indivíduo. No caso dos arquivistas, uma de suas atribuições envolve o gerenciamento da classificação dos documentos arquivísticos. Dessa forma, apenas estes podem realizar modificações nos instrumentos de gestão arquivística incorporados ao sistema, citando-se, por exemplo, a criação, modificação ou exclusão de classes, atribuição de códigos e nomenclaturas para as classes e subclasses, definição de níveis hierárquicos para a classificação, entre outros.

Frente à funcionalidade de definição de níveis hierárquicos, considera-se este fator como destaque, uma vez que de acordo com o e- 
ARQ Brasil, em determinadas classes não deve ser permitido a inclusão de documentos, pois nestes casos, os mesmos devem ser classificados apenas nos níveis subordinados. A definição de quais classes e subclasses permite a classificação de documentos também é de definição dos arquivistas, que seguem as orientações estipuladas no Código de Classificação de documentos de arquivo para a Administração Pública: Atividades-Meio e Código de Classificação de Documentos de Arquivo relativos às atividades-fim das IFES. Desse modo, as funcionalidades do SGDD incorporam-se aos instrumentos de gestão adotados6 pela instituição em questão, contribuindo para a efetivação da gestão documentam em meio digital.

\subsubsection{Relatórios e estatísticas}

Os sistemas de gestão e documentos digitais apresentam como uma de suas funcionalidades de maior repercussão no apoio aos gestores das informações, a emissão de relatórios, planilhas e demais registros estatísticos referentes à produção documental. Tais funcionalidades dificilmente são alcançadas em acervos em formato convencional e, portanto, configuram-se como uma qualidade indispensável para o atual contexto tecnológico informacional.

Tomando-se como exemplo o SGDD da UFFS, este disponibiliza opções de emissão de relatórios e gráficos estatísticos que podem se referir à produção, tramitação, eliminação, e demais parâmetros definidos pelo consulente (autorizado a realizar tal operação) referente à produção documental. Para ilustrar com maior exatidão esta funcionalidade, citamse os principais parâmetros que podem ser utilizados:

a) delimitação de acordo com o período de criação dos documentos (por. ex.: 13/05/2012 à 25/06/2012);

b) delimitação de acordo com o setor de origem (criação) e tramitação (onde se localizam) dos documentos;

c) delimitação de acordo com a classificação nas classes e subclasses, permitindo a mensuração da quantidade de documentos classificados em cada nível; e

d) espécies documentais criadas por cada setor ou de uso geral, identificando detalhadamente a produção documental da Instituição.

A emissão de relatórios pelos SGDD retratam a gestão dos documentos arquivísticos digitais e físicos de determinada Instituição, tornando-se função preponderante para se constituir um diagnóstico da situação documental. É possível, inclusive, identificar períodos de aumento, estabilidade e declínio da produção documental referente a toda instituição ou mesmo para determinado setor/unidade. O planejamento de

${ }^{6}$ A UFFS adota os instrumentos definidos pelo SIGA, órgão que tem dentre seus objetivos, integrar e coordenar as atividades de gestão da Administração Pública Federal do Brasil. 
ações de longo prazo para a gestão da informação arquivística necessita de subsídios consistentes para atingir aos objetivos que se almejam. Os relatórios do SGDD cumprem com essa função.

\subsection{Avaliação dos documentos em um SGDD}

\subsubsection{Definição de prazos de temporalidade}

A atividade de avaliação de documentos mantém uma relação direta com a classificação, pois de acordo com os preceitos da gestão documental, constituem-se de etapas sequentes. No caso do SGDD da UFFS, no momento de inserção (criação) das classes e subclasses do código de classificação da Instituição, o sistema possibilita a definição da temporalidade correspondente a cada nível. Dessa forma, ao se classificar um documento em determinada classe ou subclasse, automaticamente este recebe a temporalidade estipulada.

Considerando que os SGDD "compreendem" a temporalidade das classes e subclasses através de dados quantificáveis (em anos, meses e dias, conforme o e-ARQ Brasil), gera-se um impasse frente aos instrumentos de temporalidade utilizados pelas instituições. Isso decorre, pois muitos documentos não apresentam uma previsão exata de temporalidade na fase corrente e intermediária, recebendo definições expressas como, "enquanto vigora", "até aprovação das contas", "enquanto vigente", entre outras variáveis. Desse modo, muitos documentos não teriam condições de receber prazos quantificáveis nos sistemas. Como solução é necessário estabelecer prazos quantificáveis para todas os níveis de arquivamento que não apresentavam previsão exata da temporalidade.

Este cenário retrata uma realidade vivenciada por grande parte das instituições, principalmente as públicas, onde a avaliação de documentos (incluindo-se a definição de prazos, estudo e previsão de temporalidade, atendimento aos prazos previstos nas tabelas, etc.) requer recursos e esforços dispendiosos para que seja efetivada. Considerando que a avaliação define a existência temporária ou "eterna" de um documento, sua execução depende de um estudo prévio, crítico e racional frente à importância do conteúdo registrado nos documentos. E essa consideração se aplica do mesmo modo aos documentos digitais.

A definição de prazos exatos para a temporalidade dos documentos inseridos ou referenciados em um SGDD, devem estar em consonância com à classificação, pois as tarefas são ambas dependentes do pensamento racional e reflexivo do ser humano, algo não contemplado pela tecnologia. Além disso, quando se trata da informação arquivística, suas especificidades, caráter orgânico, multiplicidade de formas e apresentações, tornam-lhe elementos únicos, cujas características não estão previstas na linguagem lógica da tecnologia. 


\subsubsection{Gestão da temporalidade}

Os SGDD apresentam a possibilidade de emissão de relatórios referentes à produção documental, e o mesmo se aplica para a temporalidade dos documentos arquivísticos. Novamente, citando-se o SGDD da UFFS, possibilita-se a emissão de relatórios completos da temporalidade e destinação, relatórios parciais de acordo com determinadas classes e/ou subclasses do código de classificação ou de acordo com determinados prazos de guarda estipulados para os documentos. Tais relatórios são subsídios primordiais para que os arquivistas acompanhem e gerenciem os prazos de temporalidade dos documentos. Enquanto no meio físico os documentos que se acumulam (muitas vezes motivado pela inoperância da avaliação) são visíveis, no meio digital, o mesmo não acontece, pois as massas documentais ficam "ocultas" em bancos de dados, servidores institucionais e, mais comumente, nas estações de trabalho das unidades administrativas. Neste sentido, a avaliação de documentos arquivísticos digitais é tão relevante quanto no meio físico.

Além disso, o processo de avaliação de documentos públicos segue preceitos legais para que possam ser eliminados, e o mesmo se aplica aos criados e tramitados exclusivamente em meio digital. Os documentos arquivísticos, que porventura venham a ser criados e mantidos em um SGDD, deverão ser avaliados por uma Comissão Permanente de Avaliação de Documentos, e suas decisões quanto à eliminação de documentos, publicadas em boletins oficiais (de preferência de grande circulação), possibilitando que direitos e interesses de terceiros, relacionados a tais documentos, possam ser reclamados.

\section{Conclusão}

A iniciativa da gestão dos documentos digitais por meio de sistemas informatizados decorre da mudança que ocorre nos contextos institucionais, nos quais a informação digital serve como elemento de subsídio para a resolução de tarefas e tomada de decisões. Entretanto, ainda que a tecnologia auxilie a gestão das informações, é necessário um longo tempo para que esta prática torne-se usual. A falta de conscientização dos gestores, insuficiência de profissionais capacitados, cultura resistente às mudanças ou mesmo tecnologias sem funcionalidades voltadas à gestão arquivística, comprometem a criação de contextos informacionais com valorização do caráter arquivístico. No caso do SGDD da UFFS, este se apresenta como uma iniciativa inovadora e necessária no atual paradigma, no qual as informações arquivísticas voltam-se para o meio digital.

Considerando especificamente as atividades de classificação e avaliação de documentos em um ambiente digital, uma série de benefícios à gestão podem ser citados, como: acompanhamento e controle efetivo 
das tarefas de classificação e avaliação; aplicação das atividades arquivísticas aos documentos digitais; automatização de procedimentos e tarefas; além do acompanhamento e planejamento da gestão através de relatórios e dados estatísticos. No meio físico, embora tais procedimentos sejam desenvolvidos com persistência pelos arquivistas, são poucos os casos que alcançam resultados efetivos, pois demandam de estrutura e recursos que, na maioria das vezes, não são disponibilizados ou inexistem no âmbito das instituições.

A implementação de SGDD, que seguem os requisitos do e-ARQ Brasil, possibilitam a execução da gestão documental totalmente em ambiente eletrônico (alcançando o conceito de SIGAD), apresentando-se como um avanço significativo na área da tecnologia voltada à informação arquivística.

Conclui-se que um SGDD contribui significativamente para a gestão informacional de uma organização, desde que atendidos os preceitos e recomendações arquivísticas. A tecnologia, por si só, não é capaz de garantir a qualidade que a informação arquivística necessita para auxiliar no alcance dos objetivos que as organizações se propõe.

\section{Referências}

ARQUIVO NACIONAL (Brasil). Conselho Nacional de Arquivos (CONARQ). Classificação, temporalidade e destinação de documentos de arquivo relativos às atividades-meio da administração pública. Rio de Janeiro: Arquivo Nacional, 2001

BALLONI, A. J. Por que gestão em sistemas e tecnologias de informação. Centro de Pesquisa Renato Archer (Cenpra). 2003.Disponível em: <http://www.ccuec.unicamp.br/revista/infotec/artigos/GESITI_FINAL.pdf >. Acesso em: 15 mar. 2012.

BERNARDES, I. P. Como avaliar documentos de arquivo. São Paulo: Arquivo do Estado, 1998. (Projeto como fazer, v.1). Disponível em: $<$ http://www.arqsp.org.br/arquivos/oficinas colecao como fazer/cf1.pdf

>. Acesso em: 25 mar. 2012.

BERNARDES, I. P.; DELATORRE, H. Gestão documental aplicada. São Paulo: Arquivo Público do Estado de São Paulo, 2008.

BRITO, D. M. A informação arquivística na arquivologia pós-custodial. Arquivística.net, Rio de Janeiro, v. 1, n. 1, p. 31-50, jan./jun. 2005. Disponível em: <http://dici.ibict.br/archive/00000905/01/AN-200512\%5B1\%5D.pdf>. Acesso em: 15 mar. 2012.

CARVALHO, E. L.; LONGO, R. M. J. Informação orgânica: recurso estratégico para tomada de decisão pelos membros do Conselho de Administração da UEL. Inf.Inf., Londrina, v. 7, n. 2, p. 113-133, jul./dez. 2002.

CONSELHO INTERNACIONAL DE ARQUIVOS (CIA). Documentos de arquivo electrónicos: manual para arquivistas. Comité de Arquivos Correntes em 
Ambiente electrónico Estudo N.16, 2005. Disponível em: <http://dgarq.gov.pt/files/2008/10/ica estudo16.pdf>. Acesso em: 12 mar. 2012.

CONSELHO NACIONAL DE ARQUIVOS (CONARQ). E-ARQ Brasil: modelo de requisitos para sistemas informatizados de gestão arquivística de documentos. Câmara Técnica de Documentos Eletrônicos (CTDE). Rio de Janeiro, 2011. Disponível em: <http://www.siga.arquivonacional.gov.br/media/earqbrasil2011.pdf>.

Acesso em: 15 mar. 2012.

FLORES, D. Análise do programa de legislação educacional integrada Prolei: uma abordagem arquivística na gestão eletrônica de documentos GED. 2000. 145f. Dissertação (Mestrado em Engenharia da Produção) Programa de Pós-Graduação em Engenharia da Produção, UFSM, 2000.

GONÇALVES, J. Como classificar e ordenar documentos de arquivo. São Paulo: Arquivo do Estado, 1998. (Projeto como fazer, v.2 ). Disponível em:

<http://www.arqsp.org.br/arquivos/oficinas colecao como fazer/cf2.pdf

$>$. Acesso em: 20 fev. 2012.

LOPES, L. C. A gestão da informação: as organizações, os arquivos e a informática aplicada. Rio de Janeiro: APERJ, 1997.

NEGREIROS, L. R. Sistemas eletrônicos de gerenciamento de documentos arquivísticos: um questionário para escolha, aplicação e avaliação. 2007. 246f. Dissertação (Mestrado em Ciência da Informação) - Programa de Pós-Graduação em Ciência da Informação, Escola de Ciência da Informação, UFMG, 2007.

RIBEIRO, M. L. Preservação do patrimônio documental do INPE: desafios e soluções encontradas. In: CONGRESSO BRASILEIRO DE ARQUIVOLOGIA, 16., 26-27 ago. 2010. Anais... Santos: AAB, 2010.

RONDINELLI, R. C. Gerenciamento arquivístico de documentos eletrônicos: uma abordagem teórica da diplomática arquivística contemporânea. 2a ed. Rio de Janeiro: FGV, 2004.

ROUSSEAU, J.; COUTURE, C. Os fundamentos da disciplina arquivística. Lisboa: Publicações Dom Quixote, 1998. (Nova enciclopédia, 56). 